\title{
Optimal control-based price strategies for smart fishery ports micro-grids
}

\author{
Ateyah Alzahrani ${ }^{1,2}$, Ioan Petri ${ }^{1}$, Yacine Rezgui ${ }^{1}$, Ali Ghoroghi ${ }^{1}$ \\ ${ }^{1}$ BRE Trust Centre for Sustainable Engineering, Cardiff University, Cardiff, United Kingdom \\ ${ }^{2}$ School of Engineering, Al-Qunfudah, Umm Al-Qura University, Makkah, Saudi Arabia \\ Alzahraniaa2@cardiff.ac.uk \\ Aakzahrani@uqu.edu.sa
}

\begin{abstract}
The recent ongoing digital transformation of the energy landscape provides new opportunities to decarbonise energy-intensive industries, including the fish processing sector. The paper explores the potential of deploying multi-vector smart micro-grid solutions in fishery ports, sourced from dispatchable renewable generation, including solar energy. This is demonstrated in the Milford Haven Port in South Wales, United Kingdom. The proposed system is modelled using control scenario developed based on data and energy models of the port. The control scenario makes energy use decisions based on the availability of dispatchable renewable sources and the price of energy from the local energy market. Also, we consider local energy storage by utilising the local electric fishing boat fleet as an alternative energy storage system. The results demonstrate optimised energy use through multi-vector smart micro-grid model by providing more than 70 percent reduction of energy use from grid.
\end{abstract}

Keywords- Control Strategy; Carbon Emission; Energy; Smart Grid; Price; Peer-to-Peer;

\section{INTRODUCTION}

The fish processing industry is a high consumer of fossil fuel energy with commensurate levels of carbon emissions [1-4], circa $4 \%$ of total global greenhouse gas emissions [5, $6]$. Furthermore, the total human consumption of seafood has increased from 20 million tons in 1950 to more than 136 million tons in 2014 [7]. This rapid growth in seafood consumption has led to increased demands on the fish processing industry, reflected by a drastic increase in its energy use. The global investment in fish products has increased significantly during the last 40 years from EUR 8 billion to about EUR 133 billion in 2017 [7]. In this paper, the fish processing industry is considered to include all operations required to catch and prepare fish and other seafood to create the final product delivered to customers [8]. This activity requires intensive on-site energy [9] throughout the fish production lifecycle-from the fishing stage to the freezing and packaging process - that is mainly derived from electricity and liquid fuels [10]. Electricity is typically used to power processing equipment, lighting, cooling, and freezing [11]. A wide range of variables impact energy consumption in the fish processing industry, including the age of the plant, level of automation, and type of production process. Furthermore, a seafood product production line can involve heating, cooling, and other types of equipment [12]. According to the Irish seafood development agency, Bord Iascaigh Mhara, about 15\% of global fish processing industry energy consumption is related to refrigeration and air conditioning [13]. $978-1-7281-3401-7 / 18 / \$ 31.00$
Considering the intensive energy use of such cooling systems, any inefficiency can result in sizeable quantities of emissions from refrigerant gases such as ammonia [14]. However, the smart grid concept presents a significant opportunity to upgrade the fish processing industry to use smart, sustainable, and clean dispatchable energy sources, which can also deliver long-term economic benefits $[3,15]$. A smart grid is "an electricity network that efficiently integrates the behaviour and actions of all users connected to it (suppliers, consumers, and those that do both) in order to ensure economic efficiency and to provide sustainable energy systems with low losses and high levels of quality, the security of production, and safety" [16]. Prousalidis et al. [17] discussed the role of port site smart micro-grids in decreasing environmental impacts and investigated the capability of reverse cold ironing to meet the energy requirements of berthed vessels. Another study [5] examined the application of a smart micro-grid at a seaport to study the applicability of installing renewable energy resources and using compressed air energy storage. Two port authorities using offshore energy management systems are compared by [18]. The study found that implementing an energy management system in ports would help minimise energy costs and improve energy quality at the port. In previous study by the same researchers developed a model of a smart micro-grid [19] on a fishing port, and the study showed the feasibility of the effectiveness of the microgrid to achieve the required balance and autonomy with renewable energy sources available at the port with the importance to provide energy storage systems to meet the energy demand in 24 hours a day.

This study investigates the energy usage of the fish processing industry at a case study port and evaluates a method to maximise the use of renewable energy sources in these energy clusters via a smart grid approach while applying price-based control considering optimised trading of energy. Given the above review of the state-of-the-art of smart grids in the fishing industry and smart grid technology, this study makes the following contributions:

- A price-based control model is developed for the fish processing industry informed by complex energy flows and the price of electricity.

- Utilising the local electric fishing boat fleet as an alternative energy storage system.

- A P2P energy sharing control algorithm is proposed to manage intra-industry energy surplus at the site level.

Section II reviews related studies in the field of smart micro-grids, Section III presents the methodology, Section IV and V present the technical aspects including algorithms (C)2021

IEEE 
used to test various scenarios. Section VI presents scenario results. The conclusions are presented in Section VII.

\section{RELATED WORK}

The smart port concept, including virtual energy plants for ports, can have a significant impact on energy savings and can advance the promotion of renewable energy sources [2].Ramos et al. [20] investigated the use of a tidal energy farm to meet the electricity consumption of a port in Spain using a thermal energy storage model. The results indicated that a tidal farm containing 25 turbines with a $400-\mathrm{kW}$ capacity could meet the port's electricity requirements. However, their study focused only on applying renewable energy sources on site and did not propose an energy management system for the site. Misra et al. [4] suggest the use of a renewable energy-based micro-grid for a port site, estimating that $5 \mathrm{MW}$ of renewable energy was required and could be delivered by a $6.5 \mathrm{MW}$ windfarm using about 20,000 units of battery storage. However, the increased amount of battery storage required made this option too expensive for the community. Prousalidis et al. [17] discussed the role of port site smart micro-grids for decreasing environmental impacts and investigated the capability of reverse cold ironing to meet the energy requirements of berthed vessels. Finally, Misra et al. [5] examined the application of a smart micro-grid at a seaport to study the applicability of renewable energy resources for compressed air energy storage. Zhang et al. [21] introduced a strategy for sharing energy from a local microgrid with the energy market in a research report. The research is based on distributed generation in a proposed microgrid that includes diesel engines, fuel cells, and renewable energy resources. According to the research, the proposed approach resulted in the discovery of an optimum strategy for engaging with the energy market and the decrease of microgrid operating costs. Song and $\mathrm{Qu}$ [22] developed a new real-time pricing algorithm, which aimed to fix the issues of weak convergence in the current pricing model. According to the authors, a new approach can improve convergence efficiency and could be extended to large clients. Another study authored by Khomami et al. [23] developed a pricing strategy for energy management in smart micro-grids which aims to maximize profits of the operation taking in consideration different constraints. The study is based on distributed generation in a proposed microgrid that includes micro gas turbine, smart homes, and renewable energy resources. The authors claimed that the simulation results of different scenarios provide sufficient performance of the proposed strategy. On the other hand, Peer-to-Peer (P2P) energy trading has been presented as a next generation energy management system that can enable prosumers in a smart energy community to share their extra energy with others. To accomplish such energy trading, the $\mathrm{P} 2 \mathrm{P}$ mechanism needs a robust decision-making process and a reliable mathematical model that will ensure shared interest and optimal motivation between prosumers [24, 25]. Several studies have applied game theory approaches to P2P energy trading due to their feasible and effective means of modelling the energy management system.

\section{METHODOLOGY}

The study presented in this paper was developed in the context of the EU INTERREG piSCES project as the Smart Energy Cluster for the Fish Processing Industry. The objective of the piSCES project is to develop smart energy grids and management solutions to reduce the costs and carbon footprint of energy networks in the fish processing industry. Figure 1 schematic of smart grid development approach for fish processing industries and fishery port for this study. The initial stage of this study was to capture data from a fish processing port site consisting of interviews with district stakeholders, site visits, energy auditing, and data analysis to obtain detailed information on its energy systems. We then developed a simulation model for the processing buildings using three pieces of software: DesignBuilder, EnergyPlus, and MATLAB/Simulink. The first step in constructing the simulation model was creating the processing building geometries using DesignBuilder based on the site-collected data, including site location, weather data, operation time, equipment specification, etc. The DesignBuilder then interacted with the EnergyPlus simulation engine to calculate the annual energy consumption, total operation cost, and quantity of emissions produced during a one-year period for each building. The next step was to investigate the capability of simulating energy use at the fishery port to inform energy usage strategies and reduce carbon emissions.

The use of smart micro-grid systems provides an opportunity for the fish processing industry to become more sustainable while reducing operation costs by reducing energy loss and efficiently using locally generated energy. Accordingly, a smart micro-grid for the fishery processing industry was developed using the MATLAB/Simulink platform in this study.

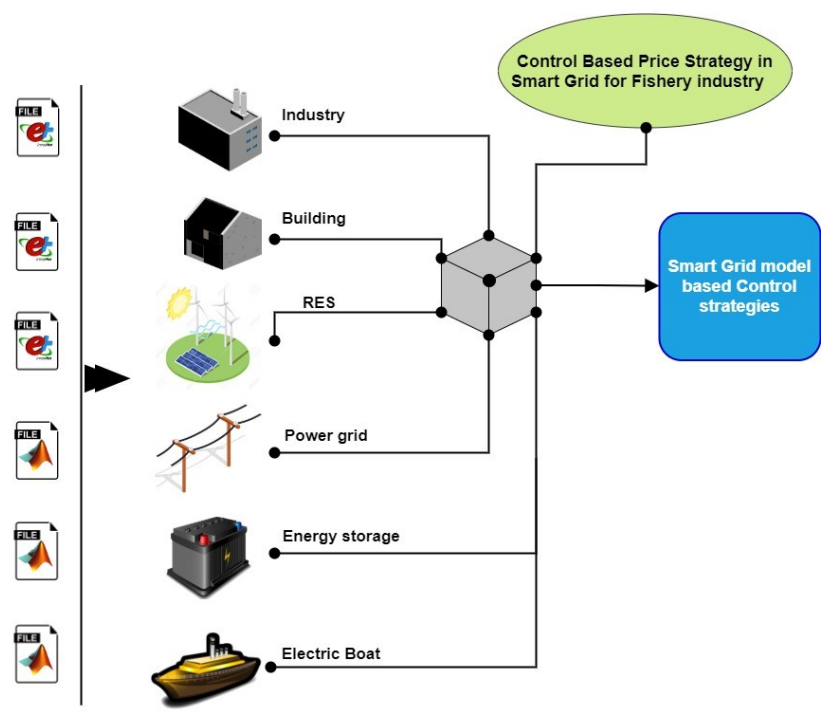

Figure 1 Schematic of smart grid development approach for fish processing industries

This smart micro-grid consisted of a load pattern, grid model, energy storage system, renewable energy generation, and control strategy. The results of the integration of these simulation components were used to identify several critical parameters in the deployment of a 
smart micro-grid in this application, such as the required battery storage system capacity, the energy consumption behaviour, and the energy generation and power use from the national grid. After developing the smart micro-grid, a surplus power distribution strategy was optimised by developing a price-based control strategy that considers the price of buying and selling power to integrate power sharing across the fish processing industry energy community that enables energy to be shared within the community instead of selling power to the grid. It is expected that this approach can help to build a smart energy community at fishery ports.

\section{SYSTEM MODEL COMPONENTS}

The proposed smart micro-grid was simulated and tested using MATLAB/Simulink. Simulink is a block diagram environment for multidomain simulation and model-based design that supports system-level design, simulation, automatic code generation, and continuous testing and verification of embedded systems.

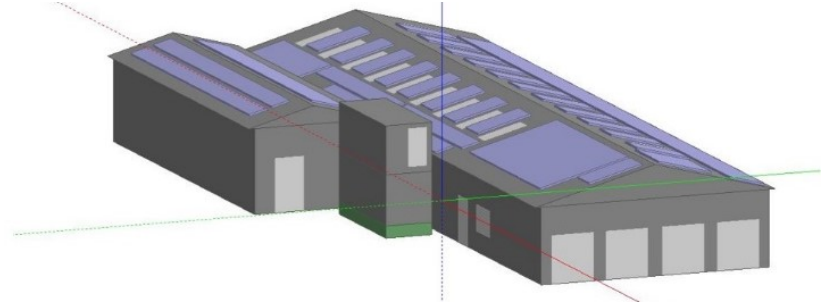

Figure 2 Simulation model of the Packaway building

For the Milford Haven site, a model was defined and developed using DesignBuilder as it shown in Figure 2 to build a smart grid model consist of energy consumption (load profile), PV system, battery system, and grid to simulate the overall operation of the system. The outputs of the simulation were used to assess the status of load, energy generation by the PV system, exchange with the grid, and the State of Charge (SOC) of the battery system. Each building in the Port of Milford Haven has a rooftop PV system with a capacity of $50 \mathrm{~kW}$ that includes a direct current (DC-DC) converter and alternating current (AC) inverter. The proposed smart grid model includes different priority levels whereby the energy produced the PV system is first utilised to operate the equipment in each building, and when the energy consumption of the building is satisfied, the excess PV-generated power is used to charge the battery system. Once the batteries are fully charged, the excess energy is sold to the national grid or to peer buildings of the micro-grid. When the PV system is not generating energy, the battery system provides the required energy to the building. The model also allows for the provision of energy from the national grid in the SOC of the battery system falls below critical levels. The system was evaluated using different battery capacities to identify the required number of batteries to meet the energy consumption of the Packaway building over a 12-month period. the solar RES data for the Packaway building on the port site was used for this purpose. The solar PV system has a capacity of $50 \mathrm{~kW}$, and its energy output was modelled as direct current (DC). However, this output must be converted to $\mathrm{AC}$ before it can be used to run the different equipment in the building. Finally, when excess power was generated, a three-phase, $50 \mathrm{~Hz}$ regulated inverter was used to feed generated energy to grid. The battery-based energy storage system (BESS) is generally based on low-voltage battery modules connected in series or parallel to achieve the desired electrical characteristics. The typical BESS comprises batteries, a battery management system, and a power conditioning system, which is connected to a safety module used to protect the entire system [26]. Fishing electric boats use fossil fuels to generate power. This use has negative impacts on the environment and leads to carbon emissions, noise, and pollution of seawater [27]. However, with the continued advance of electric road vehicle technology, similar concepts could also be used to produce efficient electric boats [28], helping to make fishing activities more environmentally friendly. Minami et al [29] detailed the main features of electric boats: quietness, low vibration, and zero carbon emissions. By replacing the use of fuel with batteries, not only can the environmental impact of the boats themselves be reduced, but their batteries can be integrated into the micro-grid using bi-directional chargers that can charge and discharge based on the employed micro-grid control strategy [30]

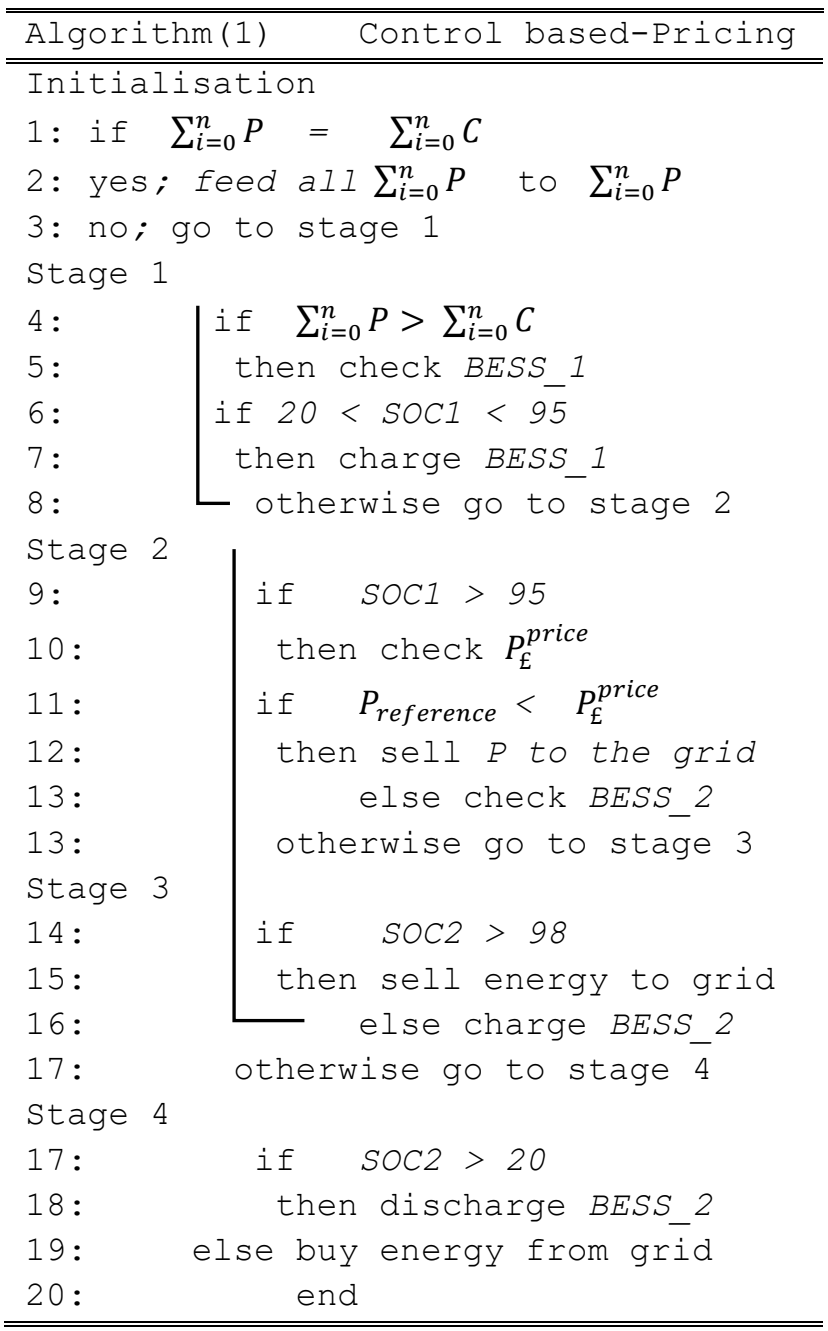

V.

REAL-TIME DECISION MAKING ALGORITHMS

The control algorithms used to manage the power distribution of the proposed fish processing industry micro- 
grid are (i) the price-based control algorithm and (ii) peerto-peer sharing algorithm.

\section{1- Price-based control algorithm}

The price-based smart grid control algorithm for the fish processing industry was developed based on the total energy production of the PV panels, the BESS capacity, and/or the electric boats to consider the price of electricity to decide between buying or selling energy. As detailed in Algorithm 1, the system checks for constraints to determine the optimum instantaneous price at the time of selling or buying. Such constraints include the SOC of the main and backup batteries as the battery status is crucial to the overall system. The control system works instantaneously and sends signals to the BESS charge controller to store or release energy according to the results of the control algorithm. In this decision-making process, the total power production ( $T_{\text {production }}$ ) is the sum of the power produced from PV panels $\left(P_{P V}\right)$ and the amount of power available in $\mathrm{n}$ batteries of the BESS and/or electric boats $P_{E B_{\text {storage }}}$ as follows:

$$
T_{\text {production }}=P_{P V}+n * P_{E B_{\text {storage }}}
$$

The total power consumption ( $\left.T_{\text {Consumption }}\right)$ is the aggregate consumption of power from the fish processing facilities in the port $\left(P_{\text {demand }}\right)$ and the power required to charge $\mathrm{n}$ batteries of the BESS and electric boats $\left(P_{E B_{\text {demand }}}\right)$ as follows:

$$
T_{\text {Consumption }}=P_{\text {demand }}+n * P_{E B_{\text {demand }}}
$$

To run the simulations, we use Simulink on a Windows 7 computer, Intel (R) Core (TM) i7-6700K CPU @ 4 GHz, with 16 GB RAM. We test different scenarios in accordance to input parameters that have been determined in the sensitivity analysis phase.

\section{2- P2P energy sharing control algorithm}

It is widely accepted that $\mathrm{P} 2 \mathrm{P}$ energy trading represents the latest generation of energy management systems. It enables prosumers in the smart energy community to sell their surplus energy to other participants. The resulting monetary benefits and efficient use of resources provides an excellent motivation to increase local energy generation from RESs and encourage domestic energy providers to share their surplus energy to the closest neighbour instead of selling it to the grid. This helps prosumers generate revenue and reduce their dependence on energy from the larger grid. This change, in turn, is reflected in a decrease in the total proportion of carbon emissions released by burning fuel or gas in traditional energy plants. The proposed control system scheme for the smart grid of the fish processing industry at the Port of Milford Haven based on P2P energy sharing.

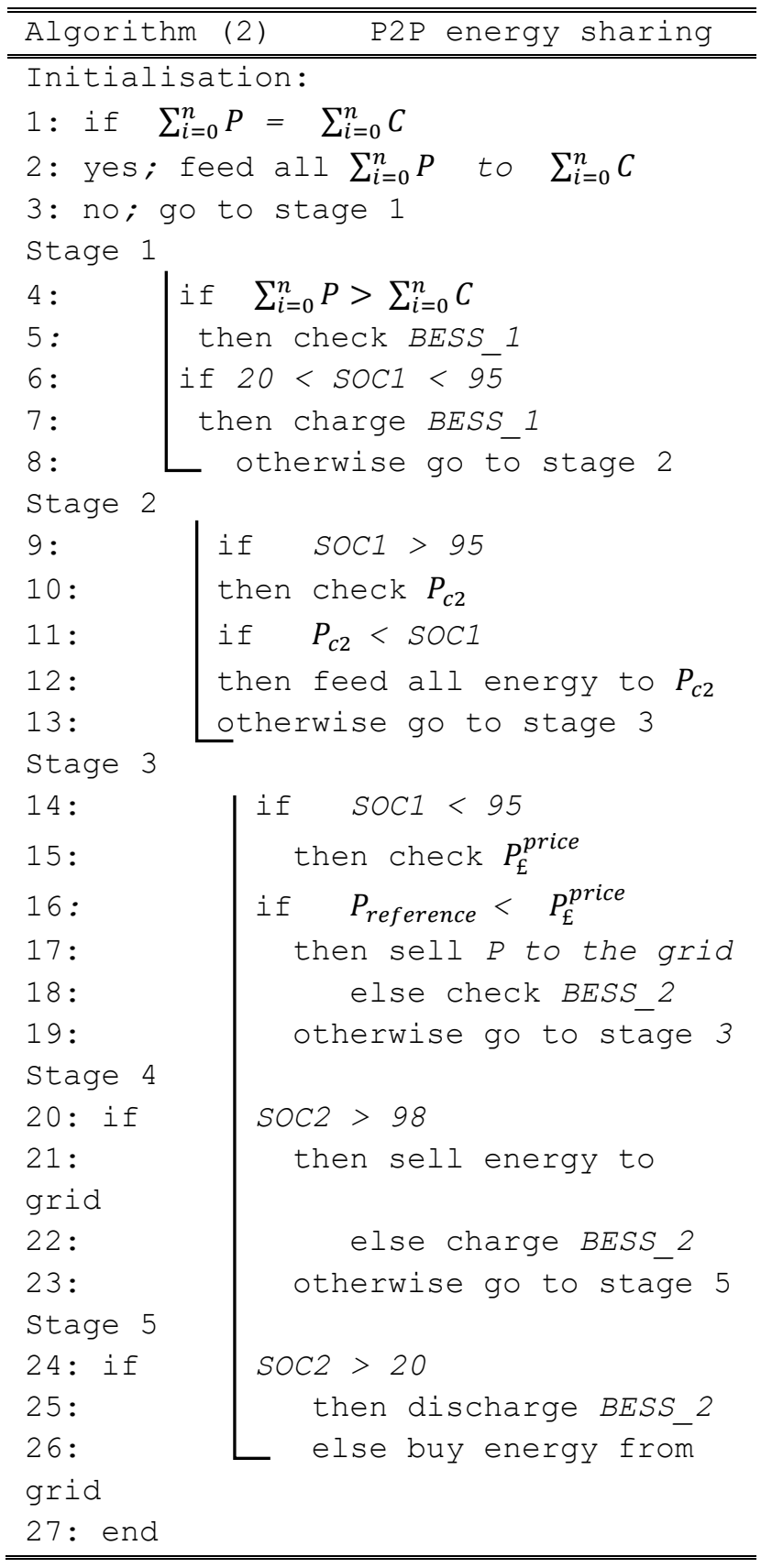

\section{RESULT AND DISCUSSION}

In this section, we discuss the evaluation of the proposed smart grid model using four scenarios to understand the impact of the price-based control strategy. These scenarios and their results are detailed as follows:

a. Optimise energy use by applying the smart grid approach: In this scenario, the objective was to maximise the use of clean energy within the micro-grid site by storing the surplus energy from the local PVs in the BESS. Each time an energy surplus is identified, it can be utilised to operate the fish processing equipment at the port, or it can be sold to the grid at a fixed tariff price. By utilising the surplus energy to support on-site operations, costs are also optimised, and carbon emissions are reduced. For this scenario, the BESS was configured with two lithium-ion batteries, a main battery, and a backup battery, to provide 
Power generation, consumption grid exchange consideing price base control

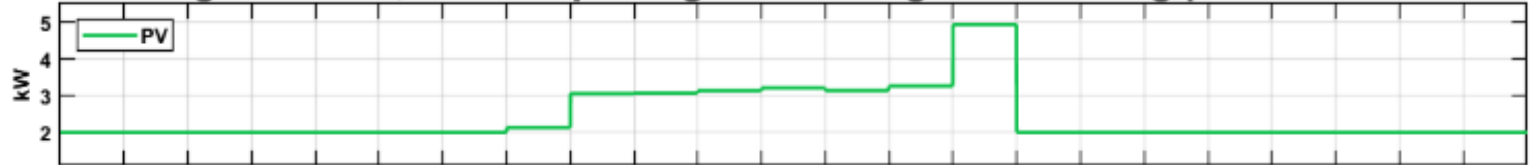

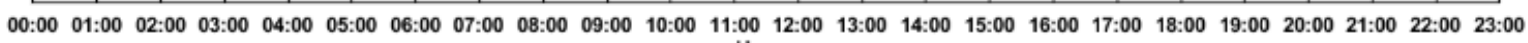
Hours

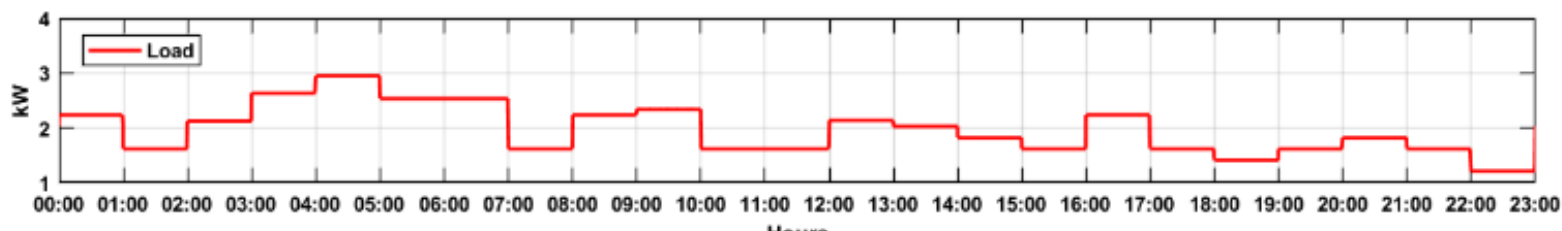

Hours
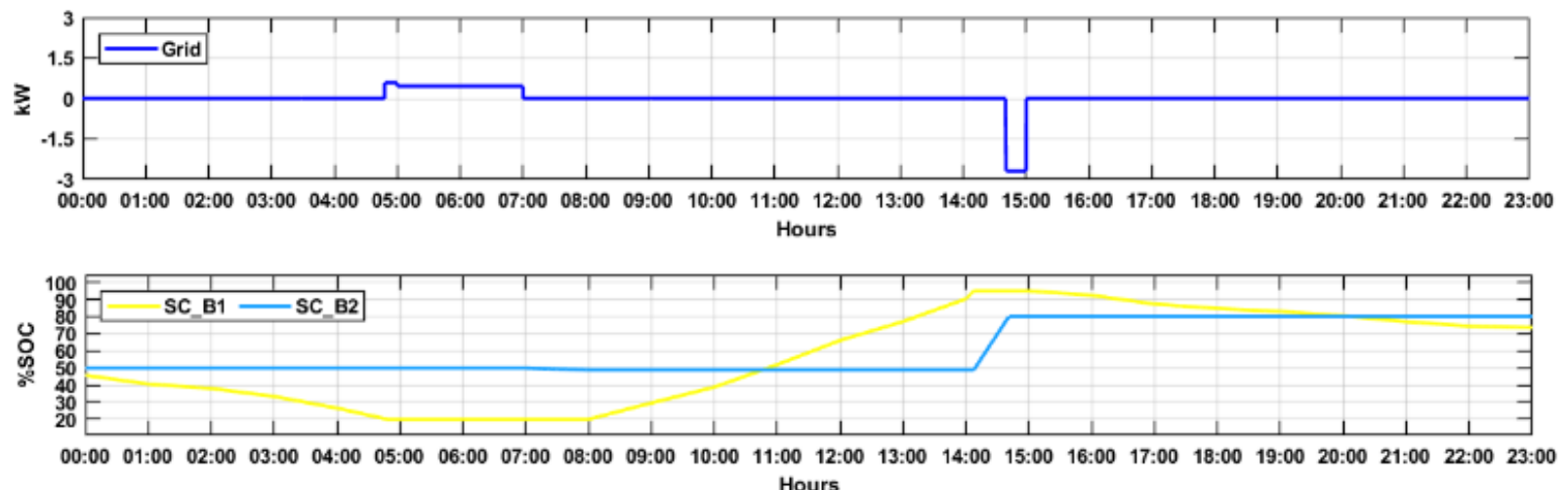
Hours

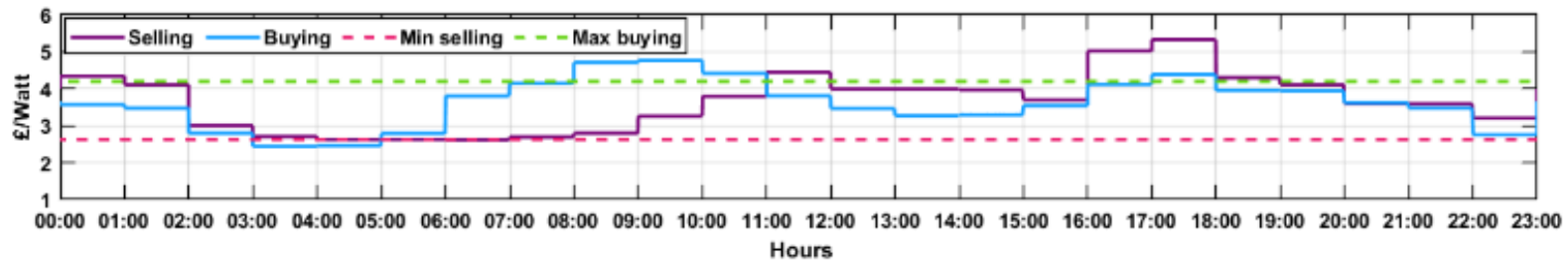

Figure 3: Optimising energy using price-based control strategy

flexibility in energy use and support the energy demand. The main battery had a capacity of 7000 Ah and the backup battery had a capacity of $5000 \mathrm{Ah}$. The reason for using two battery systems is to utilise the surplus energy generated by the PV system during daytime to meet the energy demand within 24 hours at critical times. This BESS provides a certain stability to the site while maintaining an equilibrium when required to feed energy to consuming applications. The resulting consumption and production state of the BESS when the excess electricity is utilised to operate the equipment and other power-consuming units rather than sold to the grid at a lower price can be observed in Figure 3 , which shows the state of power consumption, generation, and grid exchange over a 24-hour interval. The results show the quick response of the BESS during charging and discharging operations as well as reduced energy consumption from the national grid.

\section{b. Optimise energy use by applying the price-based control strategy:}

The objective of this scenario was to optimise energy use and associated costs by minimising the capacity of the BESS and increasing income from trading energy with the grid. In this scenario, we applied the price-based control strategy presented in Section V. The controller is connected to the local energy market to continuously retrieve the energy price based on which a set of rules are triggered to distribute energy between the local site and the main grid. For this control strategy, we set a minimum selling price of $4.2 \mathrm{£p} / \mathrm{kWh}$ and maximum buying price of $2.6 \mathrm{fp} / \mathrm{kWh}$ to enable a sell/buy decision at the site. The main grid price was based on the average European electricity market price. In this scenario, the BESS included a main and backup battery with lower capacities of $6000 \mathrm{Ah}$ and 4000 Ah, respectively. Figure 3 presents the impact of the pricebased control strategy to manage the overall energy distribution within the site. As can be observed from the results, if the grid energy price is too low, then the local system will use energy from the main grid to meet the energy demands of the fish processing site. However, if the grid energy price is too high and there is an energy surplus in the local site, then the system will sell surplus energy to the main grid. The results also reflect the fluctuation of energy price in the European energy market. Finally, it can be observed that the SOC of the main battery system discharges at night to meet the incoming energy demand of the fish processing equipment, whereas the SOC of the backup battery is stable at night because once the energy stored in the main battery is consumed, the energy demand is covered by energy from the main grid due its low energy price.

c. Optimise energy use by integrating the energy storage capacity of electric boats 
Power generation, consumption and grid exchange considering battery system and electric boats
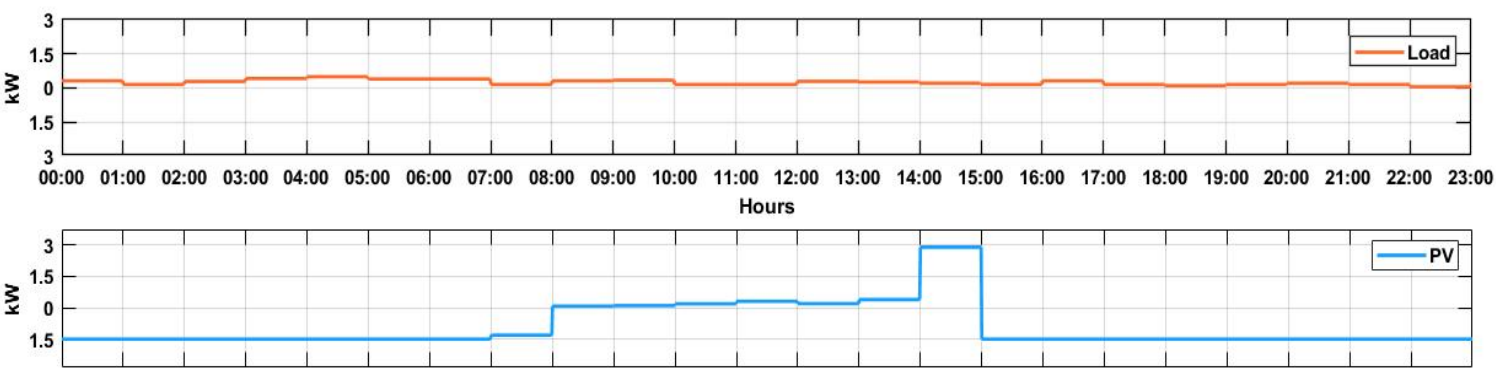

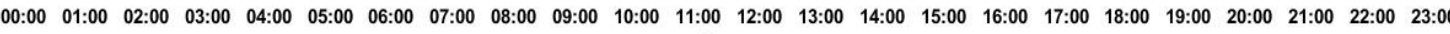
Hours

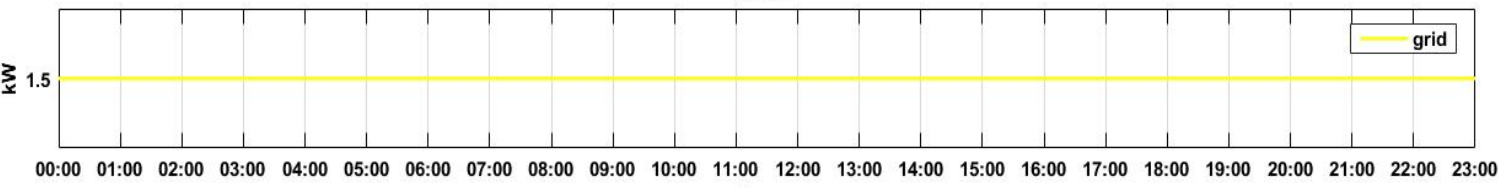

Hours

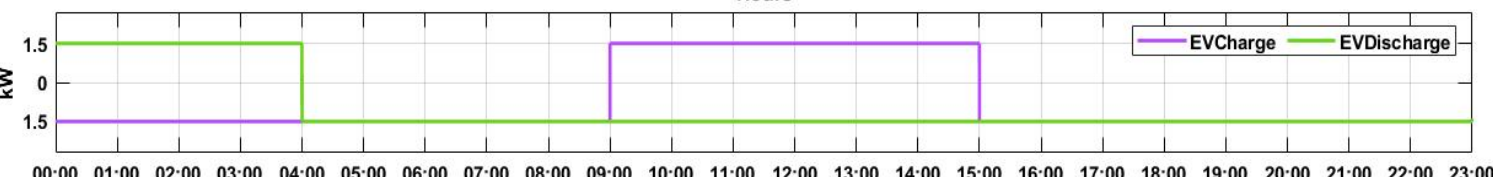

Hours

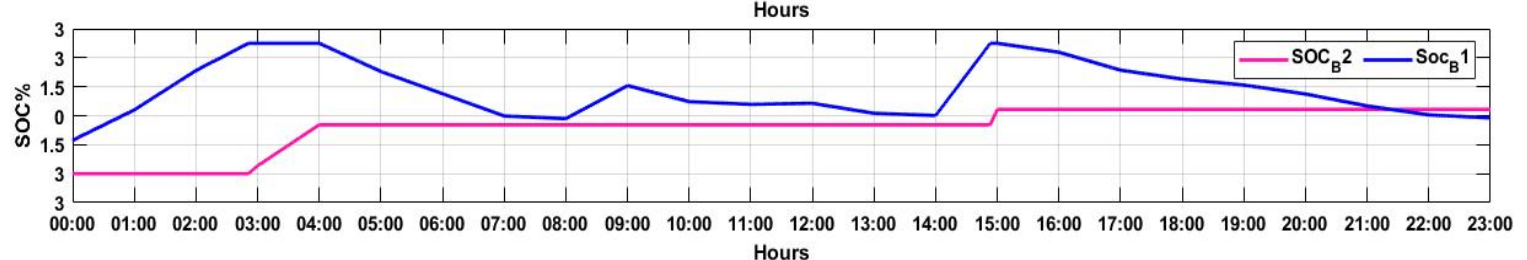

Figure 4: Optimising energy use when using electric boat battery storage

The objective of this scenario is to optimise energy use by utilising the local electric fishing boat fleet as an alternative energy storage system to minimise the main battery storage capacity on site. The use of alternative energy storage solutions such as the electric boats is expected to result in a decrease in the capital cost of energy storage equipment, considerably reducing long-term operation and maintenance costs. The algorithm for this scenario was configured to work with several electric boats identified in the port and use their storage capacities to manage the peaks in energy demand or store surplus energy once the site batteries are charged to capacity. The algorithm also ensures that at any point in time, the batteries of the electric boats will not be discharged below a threshold of $50 \%$, so the boats can always be used for fishing. In this scenario, the site energy storage capacity was set to approximately $5000 \mathrm{Ah}$ for the main battery and about $3000 \mathrm{Ah}$ for the backup battery.

Figure 4 presents the interactions between consumption and production units within the fish processing site and shows the impact of using electric boats with alternative energy storage. The results show how the electric boatbased storage system discharges and interacts with the local battery system at night and charges during the day when PV energy production is available. The results also show that the SOC of the main battery interacts with the storage systems on the electric boats by charging at night and discharging during the day. d. Optimise energy use with P2P energy sharing control strategy.

The objective of this scenario was to investigate the energy use when the site identifies high energy production from local generation sources by exploring the possibility to share or trade this energy surplus within the community of neighbouring buildings. This scenario was evaluated to identify new methods for reducing dependency on the national energy grid and encourage utilisation of clean energy resources while incentivising energy community members to become prosumers. As such, in this scenario, the surplus of energy from local energy generation was shared with local energy consumers using the P2P energy sharing strategy detailed in Section 5.2. In this scenario, we included main and backup battery systems with capacities of $7000 \mathrm{Ah}$ and $3000 \mathrm{Ah}$, respectively. Figure 8 presents the energy impact when applying the P2P control strategy, showing trends related to the energy storage system in order to support a more optimal energy use at the site by charging and discharging the BESS within a 24-hour interval. As presented in the figure, when energy generation is high and the SOC of the BESS is greater than $95 \%$, the control system will check the energy demand of the neighbourhood buildings, based on which the controller will then feed the surplus energy to the neighbouring buildings. The results also show a reduction in the quantity of energy consumed from the national grid. 
Power generation, consumption, grid exchange considering P2P energy sharing control

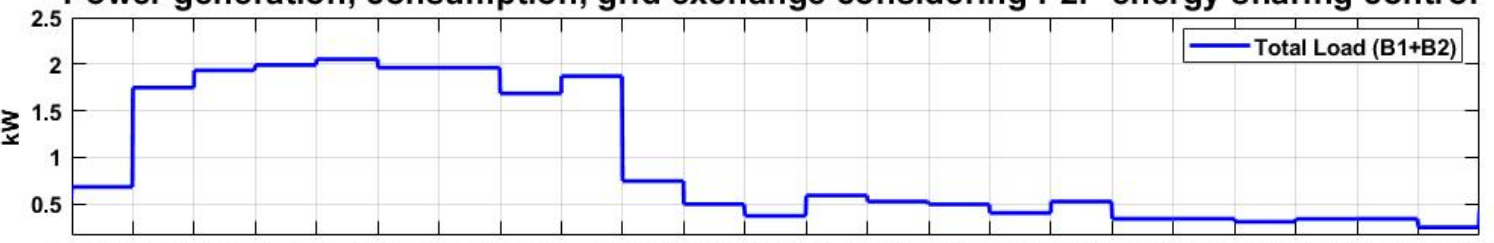

00:00 01:00 02:00 03:00 04:00 05:00 06:00 07:00 08:00 09:00 10:00 11:00 12:00 13:00 14:00 15:00 16:00 17:00 18:00 19:00 20:00 21:00 22:00 23:00 Hours

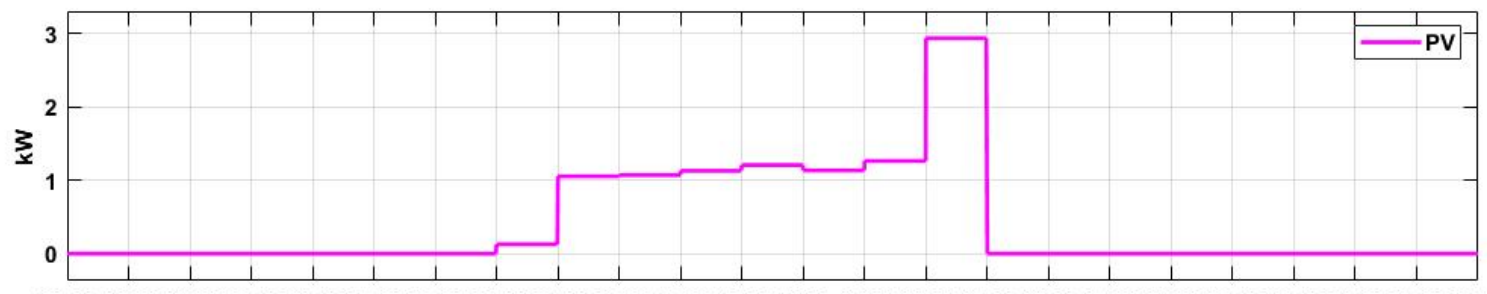

00:00 01:00 02:00 03:00 04:00 05:00 06:00 07:00 08:00 09:00 10:00 11:00 12:00 13:00 14:00 15:00 16:00 17:00 18:00 19:00 20:00 21:00 22:00 23:00 Hours

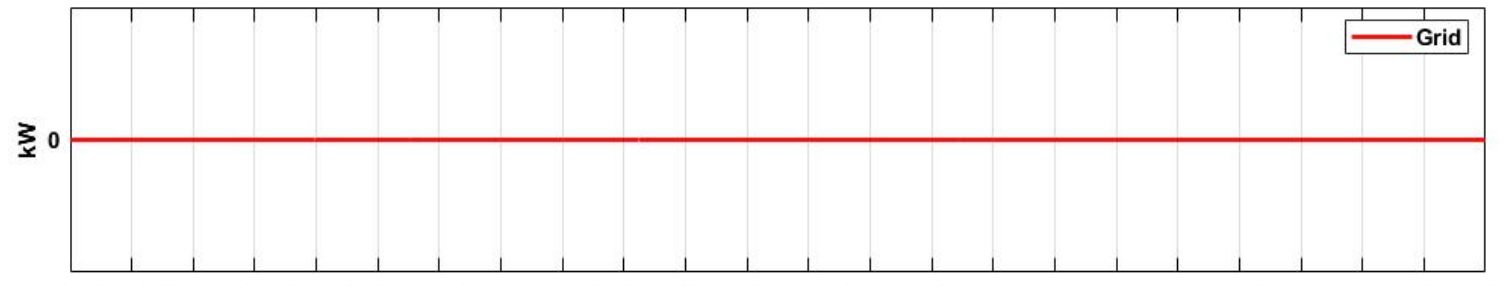
00:00 01:00 02:00 03:00 04:00 05:00 06:00 07:00 08:00 09:00 10:00 11:00 12:00 13:00 14:00 15:00 16:00 17:00 18:00 19:00 20:00 21:00 22:00 23:00 Hours

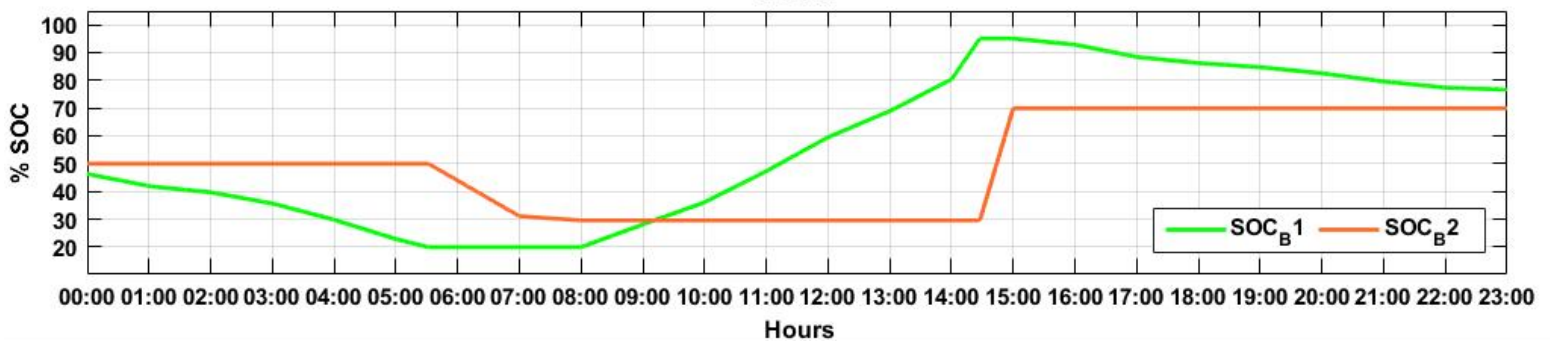

Figure 5 Optimising energy use based on a P2P energy sharing control strategy

\section{CONCLUSIONS AND FUTURE WORK}

VIII. This paper presents an analysis of a smart microgrid solution for the fish processing industry based on data collected from a real fish processing site at Milford Haven Port. The main objective of this study was to minimise carbon emissions and provide a more informed energy management strategy in relation to the surplus energy and available energy storage systems generated from dispatchable energy sources. The simulation was run in real time for 24 hours during the creation of the model in order to test the system's ability to cope with real-world conditions. The control scenario was modelled to demonstrate how smart grid solutions can be implemented in the fish processing industry. The peer-to-peer control strategy was developed to prioritise the energy demand of neighbouring buildings in the micro-grid over selling to the national grid. The results of simulations using these control strategies demonstrated how peer-to-peer energy sharing enables prosumers to participate in smart energy communities by sharing their surplus energy with other participants and provides monetary benefits and efficient use of resources. The results indicated improvements in the overall operation between agents in the smart grid when adopting either the price-based control or peer-to-peer scenarios. The results indicated improvements in the overall operation between agents in the smart grid when adopting either the price-based control or peer-to-peer scenarios. In the price-based control scenario, the control algorithm reduced energy losses and maintained energy in the system using an energy storage system. These techniques can also help to incentivise the deployment of local, renewable energy generation within the smart energy community. Furthermore, the results of this study demonstrated that applying the price-based control and peer-to-peer methods can have a significant impact on the amount of carbon emissions associated with the consumption of energy produced using traditional fossil fuels.

The findings of this study not only provide guidance for the development of low carbon smart micro-grids for the fish processing industry, sourced from dispatchable generation, but also provide an approach for the analysis of industrybased micro-grid implementation. In future research, we intend to deploy and evaluate the algorithms proposed in this study at the Port of Milford Haven site via trials and testing to identify the feasibility of the approach and capability of optimising the energy consumption and operational phases of the site, scaled up to the local community through peer-to-peer sharing. 


\section{ACKNOWLEDGMENT}

This work is part of the EU INTERREG piSCES Project: "Smart Cluster Energy System for the Fish Processing Industry", grant number: 504460 .

\section{REFERENCES}

[1] R. W. R. Parker et al., "Fuel use and greenhouse gas emissions of world fisheries," Nature Climate Change, vol. 8, no. 4, pp. 333-337, 2018/04/01 2018

[2] J. F. Muir, "FUEL AND ENERGY USE IN THE FISHERIES SECTOR: Approaches, inventories and strategic implications," FAO Fisheries and Aquaculture Circular, no. C1080, p. I, 2015.

[3] T. Lamberti, A. Sorce, L. Di Fresco, and S. Barberis, "Smart port: exploiting renewable energy and storage potential of moored boats," in OCEANS 2015-Genova, 2015, pp. 1-3: IEEE.

[4] A. Misra, G. Venkataramani, S. Gowrishankar, E. Ayyasam, and V. Ramalingam, "Renewable Energy Based Smart Microgrids-A Pathway To Green Port Development," Strategic Planning for Energy and the Environment, vol. 37, no. 2, pp. 17-32, 2017.

[5] A. Misra, G. Venkataramani, K. Panchabikesan, E. Ayyasamy, and V. Ramalingam, "Sustainable Energy Resources based Smart Microgrid towards Green Port Development-A Pathway for Ecofriendly Society," Asian Journal of Research in Social Sciences and Humanities, vol. 7, no. 3, pp. 190-200, 2017.

[6] A. Misra, K. Panchabikesan, S. K. Gowrishankar, E. Ayyasamy, and V. Ramalingam, "GHG emission accounting and mitigation strategies to reduce the carbon footprint in conventional port activities-a case of the Port of Chennai," Carbon Management, vol. 8, no. 1, pp. 45-56, 2017.

[7] FAO, "The State of World Fisheries and Aquaculture 2018-Meeting the sustainable development goals," ed: FAO Rome, Italy, 2018.

[8] M. o. E. a. C. C. Stategy, "Fish Processing Facilities Compliance Audit Report," British Coulmbia 2018.

[9] A. I. N. Daniela Borda, and Peter Raspor, Trends in Fish Processing Technologies. Taylor \$ Francis Group, 2017.

[10] K. K. Miika Rämä, "Energy solutions for Namibian fishing industry," VTT-R-1990-16, 2016

[11] S. O. Oyedepo, "Energy Use and Energy Saving Potentials in Food Processing and Packaging: Case Study of Nigerian Industries," in Bottled and Packaged Water: Elsevier, 2019, pp. 423-452.

[12] D. f. U. N. E. P. D. o. T. COWI Consulting Engineers and Planners AS, Industry and Economics, "Cleaner Production Assessment in Fish Processing," 2019.

[13] B. L. M. (BIM), "Resource Efficiency Guide for Seafood Processors ", Ireland2016.

[14] N. Shah, M. Wei, V. Letschert, and A. Phadke, "Benefits of Energy Efficient and Low-Global Warming Potential Refrigerant Cooling Equipment," 2019.

[15] J. McDonald, "Adaptive intelligent power systems: Active distribution networks," Energy Policy, vol. 36, no. 12 , pp. 4346-4351, 2008.

[16] M. Ponce-Jara, E. Ruiz, R. Gil, E. Sancristóbal, C. Pérez-Molina, and M. Castro, "Smart Grid: Assessment of the past and present in developed and developing countries," Energy strategy reviews, vol. 18, pp. 38-52, 2017.
J. Prousalidis et al., "The ports as smart micro-grids: development perspectives," Proceedings of HAEE, pp. 12-16, 2017.

[18] M. Acciaro, H. Ghiara, and M. I. Cusano, "Energy management in seaports: A new role for port authorities," Energy Policy, vol. 71, pp. 4-12, 2014.

[19] A. Alzahrani, I. Petri, and Y. Rezgui, "Modelling and implementing smart micro-grids for fish-processing industry," in 2019 IEEE International Conference on Engineering, Technology and Innovation (ICE/ITMC), 2019, pp. 1-8: IEEE.

[20] V. Ramos, R. Carballo, M. Álvarez, M. Sánchez, and G. Iglesias, "A port towards energy self-sufficiency using tidal stream power," Energy, vol. 71, pp. 432-444, 2014.

[21] Z. Zhang, H. Wang, Y. Qin, C. Gu, D. Chen, and K. Yin, "A optimization strategy of microgrid energy market based on scenario method," in 2019 IEEE 3rd Information Technology, Networking, Electronic and Automation Control Conference (ITNEC), 2019, pp. 1335-1338: IEEE.

[22] X. Song and J. Qu, "An improved real-time pricing algorithm based on utility maximization for smart grid," in Proceeding of the 11 th World Congress on Intelligent Control and Automation, 2014, pp. 2509-2513: IEEE.

[23] H. P. Khomami and M. H. Javidi, "Energy management of smart microgrid in presence of renewable energy sources based on real-time pricing," in 2014 Smart Grid Conference (SGC), 2014, pp. 1-6: IEEE.

[24] W. Tushar, C. Yuen, H. Mohsenian-Rad, T. Saha, H. V. Poor, and K. L. Wood, "Transforming energy networks via peer-to-peer energy trading: The potential of gametheoretic approaches," IEEE Signal Processing Magazine, vol. 35, no. 4, pp. 90-111, 2018.

[25] W. Tushar et al., "A motivational game-theoretic approach for peer-to-peer energy trading in the smart grid," Applied energy, vol. 243, pp. 10-20, 2019.

[26] F. Díaz-González, A. Sumper, O. Gomis-Bellmunt, and R. Villafáfila-Robles, "A review of energy storage technologies for wind power applications," Renewable and sustainable energy reviews, vol. 16, no. 4, pp. 2154-2171, 2012.

[27] M. Ferry, "Comparative Study of Hybrid Catamaran Versus Diesel Monohull Boat as Ferry for Short Distance Routes," The Indonesian Journal of Naval Architecture, vol. 1, no. 1, 2013.

[28] N. Salleh and W. Muda, "Techno-economic and sensitivity analysis for grid-connected renewable energy electric boat charging station in Terengganu," in MATEC Web of Conferences, 2017, vol. 90, p. 01016: EDP Sciences.

[29] S. Minami, T. Hanada, N. Matsuda, K. Ishizu, J. Nishi, and T. Fujiwara, "Performance of a newly developed plug-in hybrid boat," Journal of Asian Electric Vehicles, vol. 11, no. 2, pp. 1653-1657, 2013.

[30] V. D. F. Monteiro, J. C. Ferreira, and J. L. Afonso, "Smart battery charger for electric mobility in smart grids," in 1st International Conference on Smart Grids and Green IT Systems, 2012, pp. 1-6. 